\title{
Low Bone Mineral Density and Risk for Osteoporotic Fractures in Patients with Chronic Pancreatitis
}

\author{
Miroslav Vujasinovic 1,2,*(D), Lorena Nezirevic Dobrijevic ${ }^{2}$, Ebba Asplund ${ }^{2} \mathbb{D}$, Wiktor Rutkowski 1,3, \\ Ana Dugic ${ }^{2}{ }^{D}$, Mashroor Kahn ${ }^{2} \mathbb{D}^{D}$, Ingrid Dahlman 2 ${ }^{(\mathbb{D}}$, Maria Sääf ${ }^{4}$, Hannes Hagström ${ }^{1,2,5}$ \\ and Johannes-Matthias Löhr 1,3 (D)
}

1 Department of Upper Abdominal Diseases, Karolinska University Hospital, 141 86 Stockholm, Sweden; wiktor.rutkowski@ki.se (W.R.); hannes.hagstrom@ki.se (H.H.); matthias.lohr@ki.se (J.-M.L.)

2 Department of Medicine, Huddinge, Karolinska Institutet, 17176 Stockholm, Sweden; lorena.dobrijevic@stud.ki.se (L.N.D.); ebba.asplund@stud.ki.se (E.A.); ana.dugic@ki.se (A.D.); mashroor.khan@stud.ki.se (M.K.); ingrid.dahlman@ki.se (I.D.)

3 Department of Clinical Science, Intervention, and Technology (CLINTEC), Karolinska Institutet, 14186 Stockholm, Sweden

4 Endocrine and Diabetes Unit, Department of Molecular Medicine and Surgery, Karolinska Institutet, 17177 Stockholm, Sweden; maria.saaf@ki.se

5 Clinical Epidemiology Unit, Department of Medicine, Solna, Karolinska Institutet, 17177 Stockholm, Sweden

* Correspondence: miroslav.vujasinovic@sll.se; Tel.: +46-(0)-72-469-49-38; Fax: +46-(0)-8-5858-2335

check for updates

Citation: Vujasinovic, M.; Nezirevic Dobrijevic, L.; Asplund, E.;

Rutkowski, W.; Dugic, A.; Kahn, M.; Dahlman, I.; Sääf, M.; Hagström, H.; Löhr, J.-M. Low Bone Mineral Density and Risk for Osteoporotic Fractures in Patients with Chronic Pancreatitis. Nutrients 2021, 13, 2386. https:// doi.org/10.3390/nu13072386

Academic Editor: Karl Michaëlsson

Received: 24 June 2021

Accepted: 8 July 2021

Published: 13 July 2021

Publisher's Note: MDPI stays neutral with regard to jurisdictional claims in published maps and institutional affiliations.

Copyright: (c) 2021 by the authors. Licensee MDPI, Basel, Switzerland. This article is an open access article distributed under the terms and conditions of the Creative Commons Attribution (CC BY) license (https:/ / creativecommons.org/licenses/by/ $4.0 /)$.
Abstract: Introduction: Chronic pancreatitis (CP) can lead to malnutrition, an established risk factor for low bone mineral density (BMD) and fractures. This study aims to determine the prevalence of low BMD, assess fracture incidence and explore risk factors for fractures in patients with CP. Patients and methods: We performed a retrospective analysis of all patients treated for CP at Karolinska University Hospital between January 1999 and December 2020. Electronic medical records were retrieved to assess demographic, laboratory and clinical data. Patients subjected to dual-energy X-ray absorptiometry (DXA) were categorised as either low BMD or normal BMD. We investigated whether the rate of fractures, defined by chart review, differed between these groups using Cox regression, adjusting the model for age, sex and body mass index (BMI). Additional within-group survival analysis was conducted to identify potential risk factors. Results: DXA was performed in $23 \%$ of patients with definite CP. Some 118 patients were included in the final analysis. Low BMD was present in $63(53.4 \%)$ patients. Mean age at CP diagnosis in the total cohort was 53.1 years and was significantly lower in patients with normal BMD than in patients with low BMD (45.5 vs. 59.8, $p<0.001)$. Significant differences were observed in smoking status and disease aetiology, i.e., a higher proportion of patients with low BMD were current or former smokers, with nicotine or alcohol being a more common cause of CP $(p<0.05)$. Total follow-up time was 898 person-years. Fractures were found in $33(28.0 \%)$ patients: in 5 of 55 patients $(16.7 \%)$ with normal DXA and in 28 of 63 patients $(44.4 \%)$ with low BMD (adjusted hazard ratio $=3.4,95 \%$ confidence interval $(\mathrm{CI})=1.2-9.6)$. Patients with at least 3 months of consecutive pancreatic enzyme replacement therapy (PERT) or vitamin $\mathrm{D}$ treatment had a longer median time to fracture after CP diagnosis. Conclusion: DXA was only performed in $23 \%$ of patients with definite $\mathrm{CP}$ in this study, indicating a low adherence to current European guidelines. A low BMD was found in $53.4 \%$ of patients with $\mathrm{CP}$, and $44 \%$ of the patients with a low BMD experienced a fracture during follow-up. Moreover, the fracture rate in patients with low BMD increased compared to those with normal BMD.

Keywords: chronic pancreatitis; bone mineral density; osteoporosis; fracture; PERT

\section{Introduction}

Chronic pancreatitis (CP) can severely affect quality of life and precipitate lifethreatening long-term sequelae (e.g., exocrine and endocrine insufficiency, recurrent 
inflammation, persistent pain and malabsorption), including vitamin and trace mineral deficiencies. Diabetes mellitus (DM), pancreatic exocrine insufficiency (PEI), anorexia secondary to abdominal pain, nausea and vomiting, alcohol, smoking or other substance abuse and poor physical activity levels may all contribute to malnutrition in patients with CP [1].

Osteoporosis is a systemic skeletal disease characterised by low bone mass and microarchitectural deterioration of bone tissue, with a consequent increase in bone fragility and susceptibility to fracture [2]. Based on a meta-analysis, it has been estimated that nearly a quarter of patients with $\mathrm{CP}$ have osteoporosis and almost two thirds have either osteoporosis or osteopenia, making these conditions underappreciated sources of morbidity in patients with CP [3]. Current European guidelines recommend preventive measures in all patients diagnosed with $\mathrm{CP}$, with regular quantitative assessment of bone mineral density (BMD) by dual-energy X-ray absorptiometry (DXA) every 2 years in patients with confirmed low BMD. However, bone health assessments are rarely performed in routine clinical practice $[1,4,5]$. Studies investigating the clinical significance of low-trauma fractures in $\mathrm{CP}$ patients estimated a 10-year fracture prevalence of $4.8 \%$, comparable with that of "high-risk" digestive diseases such as liver cirrhosis, inflammatory bowel disease, celiac disease and patients after gastrectomy [6]. Most studies on this topic have been limited by heterogeneous data and small sample sizes not amenable to subgroup analysis $[1,3]$. This study aims to fill a gap in the literature concerning fracture incidence in CP patients treated at a high-volume European tertiary centre. Therefore, we sought to determine the prevalence of low BMD, fracture incidence and fracture risk factors in patients with $\mathrm{CP}$. In addition, we explored previously suggested contributory factors influencing fracture risk, including treatment with proton-pump inhibitors (PPI), metformin, steroids, opioids or supplementation with vitamin D or pancreatic enzyme replacement therapy (PERT).

\section{Patients and Methods}

\subsection{Study Population}

In this study, with retrospectively collected data, we first identified all patients with an international classification of diseases (ICD)-based code for CP at the Karolinska University Hospital between January 1999 and December 2020 as eligible for inclusion. Thus, patients could have a first diagnosis of $\mathrm{CP}$ before they visited our institution. We excluded patients without a Swedish personal identification number (a 12-digit number issued by the Swedish Tax Agency as a part of the population register used in Sweden), patients with missing or insufficient data in medical charts related to this study, patients without permanent residency in Stockholm County, patients in whom DXA had not been performed and patients with non-definitive $\mathrm{CP}$ diagnosis. Baseline data were collected at the first date of diagnosis at our institution. In addition, data were obtained from journal entries available from primary, secondary and tertiary care centres in Stockholm County.

\subsection{Definitions}

Aetiology of $\mathrm{CP}$ was determined according to the M-ANNHEIM classification system, and only patients with definite $\mathrm{CP}$ were included in one or more of the following groups: alcohol, nicotine, nutritional factors, hereditary factors, efferent duct factors, immunological and miscellaneous/other [7]. Definite CP was diagnosed by imaging (computed tomography, magnetic resonance imaging or both) with one or more of the following criteria: (a) pancreatic calcifications, (b) moderate or marked ductal lesions, (c) marked and persistent exocrine insufficiency defined as pancreatic steatorrhea markedly reduced by enzyme supplementation or (d) typical histology of an adequate histological specimen. Patients subjected to DXA were grouped into categories of low BMD or normal BMD based on the T-score for BMD assessed by DXA on the femoral neck or lumbar spine, with a value of 1 standard deviation (SD) below that of a healthy 30-year-old of the same sex being indicative of low BMD. In addition, patients with low BMD could be further subdivided into categories of osteoporosis (T-score below or equal to $-2.5 \mathrm{SD}$ ) or osteopenia (T-score 
between -1.0 and $-2.5 \mathrm{SD}$ ). For patients in which only the Z-score had been reported, two standard deviations below normal value were used to define low BMD [5]. Baseline was defined at CP diagnosis. While patients were included if they had received an ICD-based diagnosis code at Karolinska University Hospital between January 1999 and December 2020, the initial diagnosis could have been made earlier in primary care facilities or tertiary centres outside Stockholm. Our primary outcome was defined as time to the first of any fracture following $\mathrm{CP}$ diagnosis registered in the electronic medical system available to primary, secondary and tertiary care providers in Stockholm County. Only radiologically confirmed fractures diagnosed in primary, secondary or tertiary care centres in Stockholm County were included. Baseline data were collected concerning patients' first visit to the Pancreas Outpatient Clinic at the Department of Upper Abdominal Diseases at Karolinska University Hospital. Patients were followed until the first fracture diagnosis was recorded in the electronic medical system or death occurred. Fracture incidence was analysed for BMD after adjusting for patients' age at baseline, sex and body mass index (BMI). Additional data included the anatomical distribution of fractures, previous diagnosis of DM or PEI at time of CP diagnosis, smoking status (current, never, former) and alcohol consumption (never, ever). High alcohol consumption was defined as a daily alcohol intake of $\geq 80 \mathrm{~g}$ per day (ref number 7). Diagnosis of PEI was based on the concentration of faecal elastase-1 (levels $<200 \mu \mathrm{g} / \mathrm{g}$ were considered pathological). Information on DM was obtained from patients' medical charts. Exploratory analysis was used to investigate whether treatment with drugs that might affect fracture risk was associated with a reduced rate of fractures. Patients were defined as being on treatment if they were on stable maintenance therapy for at least 90 days after baseline with any of the following treatments: PERT, PPI, opioids, oral steroid treatment, vitamin D supplements and metformin.

\subsection{Statistics}

Categorical variables were compared using Pearson's chi-square test or Fisher's exact test as appropriate and reported as percentages and frequencies. Continuous variables, reported as means and tested for significance with a Student's $t$ test, were analysed for normality using the Shapiro-Wilk test. The risk for the primary outcome, i.e., first incident fracture after baseline, was compared between patients with normal BMD and patients with low BMD using Cox regression. Two models were considered, one crude model and one adjusted for age, sex and BMI. Age and BMI were used as continuous variables in the adjusted model. For all regression analyses, results were reported as hazard ratios (HR) and $95 \%$ confidence intervals (CI). The Kaplan-Meier method was used to estimate the cumulative incidence of fractures in all patients regarding BMD and drug therapy, and then compared using the log-rank (Mantel-Cox) test. Patients were censored at death. All statistical tests were two-sided and a $p$ value of $<0.05$ was considered statistically significant. All analyses were performed using R Statistical Software (version 4.0.3; R Foundation for Statistical Computing, Vienna, Austria).

\subsection{Ethics}

The study was approved by the Regional Ethics Committee (Swedish: Regionala Etikprövningsnämnden) in Stockholm, Dnr: 2020-02209. The committee waived the requirement for individual informed patient consent because of the retrospective nature of the study.

\section{Results}

Some 1055 patients diagnosed with $\mathrm{CP}$ were eligible for inclusion and 118 were included in the final analysis (a flowchart of patients is presented in Figure 1). In patients with a definitive diagnosis not subjected to DXA, 29\% (96/329) had suffered from fractures. This percent is on par with the proportion having suffered fractures in the group of patients who had received DXA, where $28 \%(33 / 118)$ had suffered from fractures. Of the 33 fractured patients subjected to DXA, 17 had performed DXA between CP diagnosis and 
fracture (16 had DXA following fracture incident). Baseline characteristics for patients in the DXA group at the time of CP diagnosis are presented in Table 1. DXA for assessing BMD with T-score and Z-score was performed at any time point to $\mathrm{CP}$ diagnosis and first fracture. Low BMD was present in $63(53.4 \%)$ patients. Total follow-up time was 897.6 person-years (446.2 person-years in patients with low BMD and 451.4 person-years in patients with normal BMD). Mean age at CP diagnosis in the total cohort was 53.1 years and was significantly lower in patients with normal BMD than in patients with low BMD (45.5 vs. $59.8, p<0.001)$. In addition, females were more prevalent in patients with low BMD than in patients with normal BMD $(50.7 \%$ vs. $30.9 \%, p<0.05)$. Significant differences were also observed in smoking status and $\mathrm{CP}$ aetiology. More specifically, a higher proportion of patients with low BMD were current or former smokers $(p<0.05)$, with nicotine or alcohol being a more common cause of the disease $(p<0.05)$.

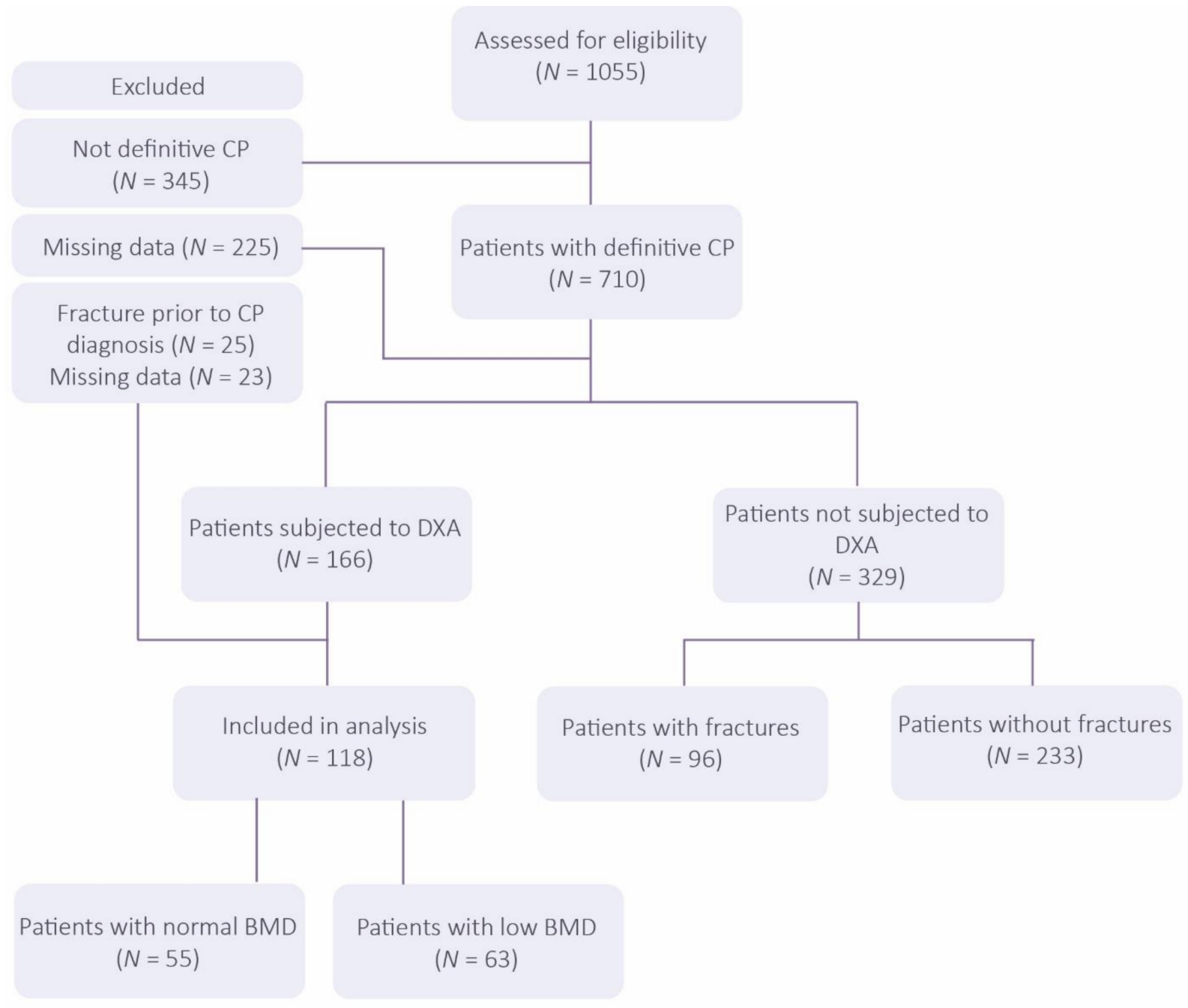

Figure 1. Flow chart of patient selection $(\mathrm{CP}=$ chronic pancreatitis; $\mathrm{BMD}=$ bone mineral density; $\mathrm{DXA}=$ dual-energy X-ray absorptiometry).

Some 33 (28.0\%) patients suffered from fractures following CP diagnosis. The overall fracture rate between the groups is listed in Table 2. Fractures were more prevalent in patients with low BMD (28/63) compared to patients with normal BMD $(5 / 55)$. Stratifying patients with low BMD into categories of osteopenia (T-score between -1 and $-2.5 \mathrm{SD}$ ) or osteoporosis (T-score below $-2.5 \mathrm{SD}$ ), a higher cumulative incidence of fractures was evident in osteoporotic patients ( $60 \%$ and $30.3 \%$ of patients, respectively). Similarly, fracture rate was significantly higher in patients with low BMD than in patients with normal BMD 
(crude $\mathrm{HR}=5.5 ; 95 \% \mathrm{CI}=2.1-14.2$ ). Adjusted for sex, age and BMI, the fracture rate remained significantly increased in osteoporotic patients $(\mathrm{aHR}=5.5 ; 95 \% \mathrm{CI}=1.9-15.8)$.

Table 1. Baseline patient characteristics.

\begin{tabular}{|c|c|c|c|c|}
\hline & $\begin{array}{c}\text { Total } \\
(n=118)\end{array}$ & $\begin{array}{l}\text { Low BMD } \\
(n=63)\end{array}$ & $\begin{array}{c}\text { Normal BMD } \\
\quad(n=55)\end{array}$ & $p$-Value \\
\hline Female sex, $n(\%)$ & $49(41.5)$ & $32(50.7)$ & $17(30.9)$ & $<0.05$ \\
\hline Follow-up (years), mean (SD) & $7.6(7.5)$ & $7.1(6.8)$ & $8.2(8.1)$ & 0.424 \\
\hline Age at $\mathrm{CP}$ diagnosis (years), mean (SD) & $53.1(16.3)$ & $59.8(11.8)$ & $45.5(17.5)$ & $<0.001$ \\
\hline Diabetes at diagnosis, $n(\%)$ & $28(23.7)$ & $16(25.4)$ & $12(21.8)$ & 0.774 \\
\hline Age group, $n(\%)$ & - & - & - & - \\
\hline$-<45$ years & $35(29.6)$ & $6(9.5)$ & $29(52.7)$ & - \\
\hline$-45-65$ years & $51(43.2)$ & $35(55.6)$ & $16(29.0)$ & - \\
\hline - $\geq 65$ years & $32(27.1)$ & $22(35.9)$ & $10(18.1)$ & $<0.005$ \\
\hline BMI, mean (SD) & $23.9(4.4)$ & $23.06(4.05)$ & $24.9(4.6)$ & $<0.05$ \\
\hline - BMI <20.0, $n(\%)$ & $25(21.2)$ & $15(23.8)$ & $10(1.1)$ & - \\
\hline$-20.1<\mathrm{BMI}<25.0, n(\%)$ & $50(42.4)$ & $33(52.4)$ & $17(30.9)$ & - \\
\hline$-25.1<\mathrm{BMI}<30.0, n(\%)$ & $30(25.4)$ & $10(15.9)$ & $20(36.3)$ & - \\
\hline$-30.1<\mathrm{BMI}, n(\%)$ & $13(11.0)$ & $5(7.9)$ & $8(14.5)$ & $<0.05$ \\
\hline Smoking status & - & - & - & - \\
\hline - Current smoker, $n(\%)$ & $42(35.6)$ & $28(44.4)$ & $14(25.5)$ & - \\
\hline - Former smoker, $n(\%)$ & $34(28.8)$ & $19(30.2)$ & $15(27.2)$ & - \\
\hline - Never smoker, $n(\%)$ & $42(35.6)$ & $16(25.4)$ & $26(47.2)$ & $<0.05$ \\
\hline \multicolumn{5}{|l|}{ Alcohol status } \\
\hline - Non-drinker & $64(54.7)$ & $28(44.4)$ & $36(66.7)$ & \\
\hline - Drinker & $53(45.2)$ & $35(55.6)$ & $18(33.3)$ & $<0.01$ \\
\hline - Data not available & 1 & 0 & 1 & \\
\hline Aetiology of CP & - & - & - & - \\
\hline - Alcohol and nicotine, $n(\%)$ & $40(33.9)$ & $27(46.6)$ & $13(26.5)$ & - \\
\hline - Nicotine, $n(\%)$ & $13(11.0)$ & $9(15.5)$ & $4(8.1)$ & - \\
\hline - Alcohol, $n(\%)$ & $7(5.9)$ & $4(6.9)$ & $3(6.1)$ & - \\
\hline - Hereditary, $n(\%)$ & $14(11.8)$ & $3(5.2)$ & $11(22.4)$ & - \\
\hline - Immunological, $n(\%)$ & $17(14.4)$ & $9(15.5)$ & $8(16.3)$ & - \\
\hline - Immunological factors and nicotine, $n(\%)$ & $0(0.0)$ & $0(0.0)$ & $0(0.0)$ & - \\
\hline - Efferent duct & $11(9.3)$ & $6(10.3)$ & $5(10.2)$ & - \\
\hline - Misc./Other, $n(\%)$ & $8(6.7)$ & $3(5.1)$ & $5(10.2)$ & $<0.05$ \\
\hline - Data not available & 8 & 2 & 6 & - \\
\hline PEI at diagnosis & - & - & - & - \\
\hline - No $n(\%)$ & $35(39.3)$ & $20(40.0)$ & $15(38.5)$ & \\
\hline - Yes $n(\%)$ & $54(60.7)$ & $30(60.0)$ & $24(61.5)$ & 1.0 \\
\hline - Missing data & 29 & 13 & 16 & - \\
\hline DXA results, median (quartiles) & - & - & - & - \\
\hline - T-score hip & $-1.47(-2.36,0.81)$ & $-2.18(-2.6,1.7)$ & $-0.3(-0.85,0.2)$ & $<0.005$ \\
\hline - T-score lower back & $-0.71(-2.0,0.55)$ & $-1,55(-2.78,-0.5)$ & $0.69(0.1,1.2)$ & $<0.005$ \\
\hline $\begin{array}{c}\text { Median time from CP diagnosis to DXA, } \\
\text { years (IQR) }\end{array}$ & $2.8(7.4)$ & $2.8(8.0)$ & $2.7(6.5)$ & 0.696 \\
\hline
\end{tabular}

$\mathrm{CP}=$ chronic pancreatitis; $\mathrm{SD}$ = standard deviation; $\mathrm{BMI}$ = body mass index; $\mathrm{PEI}=$ pancreatic exocrine insufficiency; $\mathrm{DXA}=$ dual-energy $\mathrm{X}$-ray absorptiometry. BMD = bone mineral density.

Table 2. Overall rate of fractures.

\begin{tabular}{ccccccc}
\hline & N & Event & >Person-Years & Incidence & $\begin{array}{c}\text { Crude HR } \\
\text { [CI 95\%] }\end{array}$ & $\begin{array}{c}\text { aHR * } \\
\text { [CI 95\%] }\end{array}$ \\
\hline Normal BMD & 55 & 5 & 451.4 & 1.1 & $1.0[\mathrm{ref}]$. & $1.0[\mathrm{ref}]$. \\
Low BMD & 63 & 28 & 446.2 & 6.3 & $5.5[2.1,14.2]$ & $3.4[1.2,9.6]$ \\
- Osteopenia & 33 & 10 & 248.6 & 4.0 & $3.5[1.2,10.4]$ & $2.2[0.7,6.8]$ \\
- Osteoporosis & 30 & 18 & 197.6 & 9.2 & $7.8[2.9,21.01]$ & $5.5[1.9,15.8]$ \\
\hline
\end{tabular}

$\mathrm{N}=$ number of patients; $\mathrm{HR}=$ hazard ratio; $\mathrm{aHR}=$ adjusted hazard ratio; $\mathrm{BMI}=$ body mass index; $\mathrm{CP}=$ chronic pancreatitis. Ref. = referent. $\mathrm{CI}=$ confidence interval. Time from CP diagnosis to first fracture. Incidence per 100 person-years. * Adjusted for sex, age and BMI. 
The anatomical distribution of fracture locations is given in Table 3 and illustrated in Figure 2. Fractures were evenly distributed among body regions, with hip, vertebra and wrist fractures being more prominent overall in patients with low and normal BMD.

Table 3. Fracture incidence by anatomic region.

\begin{tabular}{|c|c|c|c|c|c|c|}
\hline & \multicolumn{3}{|c|}{ Low BMD } & \multicolumn{3}{|c|}{ Normal BMD } \\
\hline & Event & Person-Years & Incidence & Event & Person-Years & Incidence \\
\hline Hip & 8 & 446.2 & 1.8 & 0 & 451.4 & 0.0 \\
\hline Vertebrae & 7 & 446.2 & 1.6 & 1 & 451.4 & 0.22 \\
\hline Rib & 1 & 446.2 & 0.22 & 0 & 451.4 & 0 \\
\hline Ankle & 2 & 446.2 & 0.45 & 1 & 451.4 & 0.22 \\
\hline Shoulder & 1 & 446.2 & 0.22 & 0 & 451.4 & 0 \\
\hline Wrist & 0 & 446.2 & 0.0 & 2 & 451.4 & 0.44 \\
\hline Clavicle & 2 & 446.2 & 0.45 & 0 & 451.4 & 0.0 \\
\hline Hand \& feet & 3 & 446.2 & 0.67 & 0 & 451.4 & 0.0 \\
\hline Knee & 1 & 446.2 & 0.22 & 1 & 451.4 & 0.22 \\
\hline Other & 3 & 446.2 & 0.67 & 0 & 451.4 & 0.0 \\
\hline
\end{tabular}

$\mathrm{N}=$ number of patients. BMD = bone mineral density. Incidence per 100 person-years.

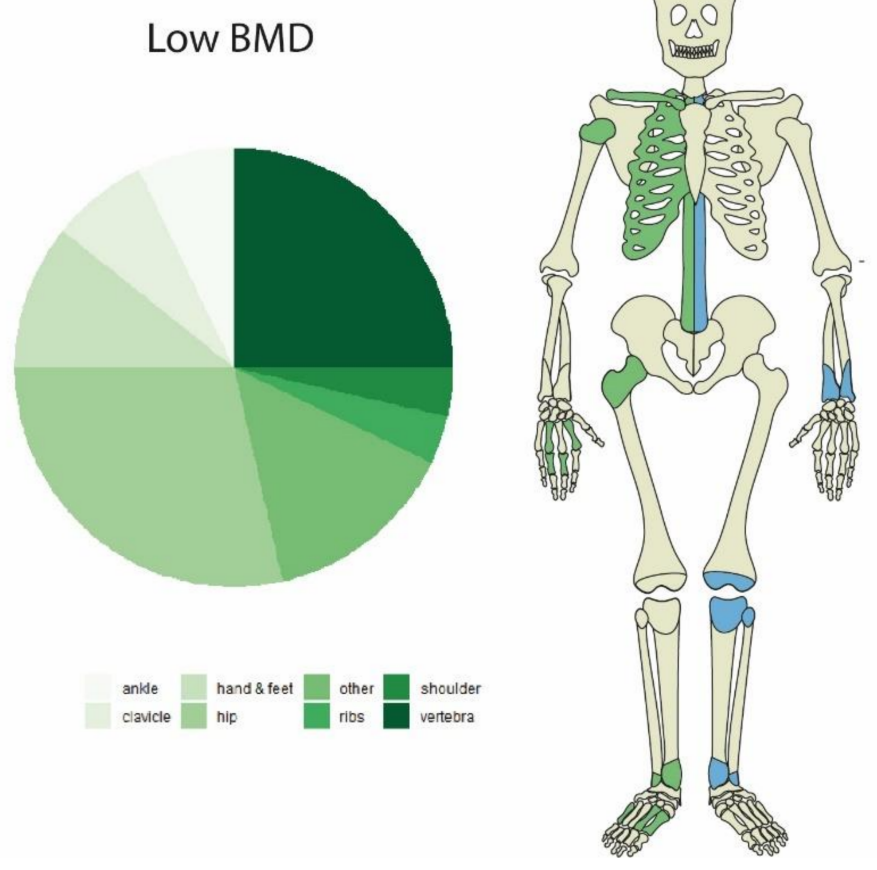

Normal BMD
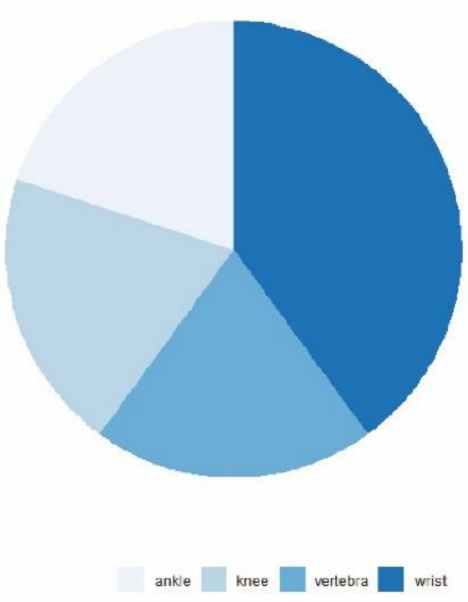

Figure 2. Distribution of fractures by bone mineral density (BMD). Fractures in both groups were evenly distributed among body regions, with hip, vertebra and wrist fractures being more prominent overall.

Median time to fracture for patients with low BMD was 9.2 years. Kaplan-Meier curves of cumulative fracture events in patients with normal BMD vs. patients with low BMD are detailed in Figure 3.

Further exploration of the influence of drug therapy before or concomitant with fracture incident on time to first fracture after CP diagnosis is summarised in Supplementary Material Figure S1 and Supplementary Material Table S1. While the low number of patients not treated with PERT needs to be considered, Kaplan-Meier estimates of median time to first fracture suggest a possible difference between patients treated with PERT supplements and untreated patients. Estimated median time to first fracture was 19.7 years (104 patients, 25 fractures) for PERT-treated patients compared to 6.7 years (14 patients, 8 fractures) to first fracture in PERT-untreated patients. A similar trend can be observed in patients treated 
with vitamin D supplements, of whom treated patients had a longer median time to first fracture. Estimated median time to first fracture was 12.2 years (48 patients, 19 fractures) for vitamin D-untreated patients compared to 31.7 years (70 patients, 14 fractures) for vitamin D-treated patients. No significant difference could be identified when assessing the influence of steroid, PPI, opioid or metformin treatments.

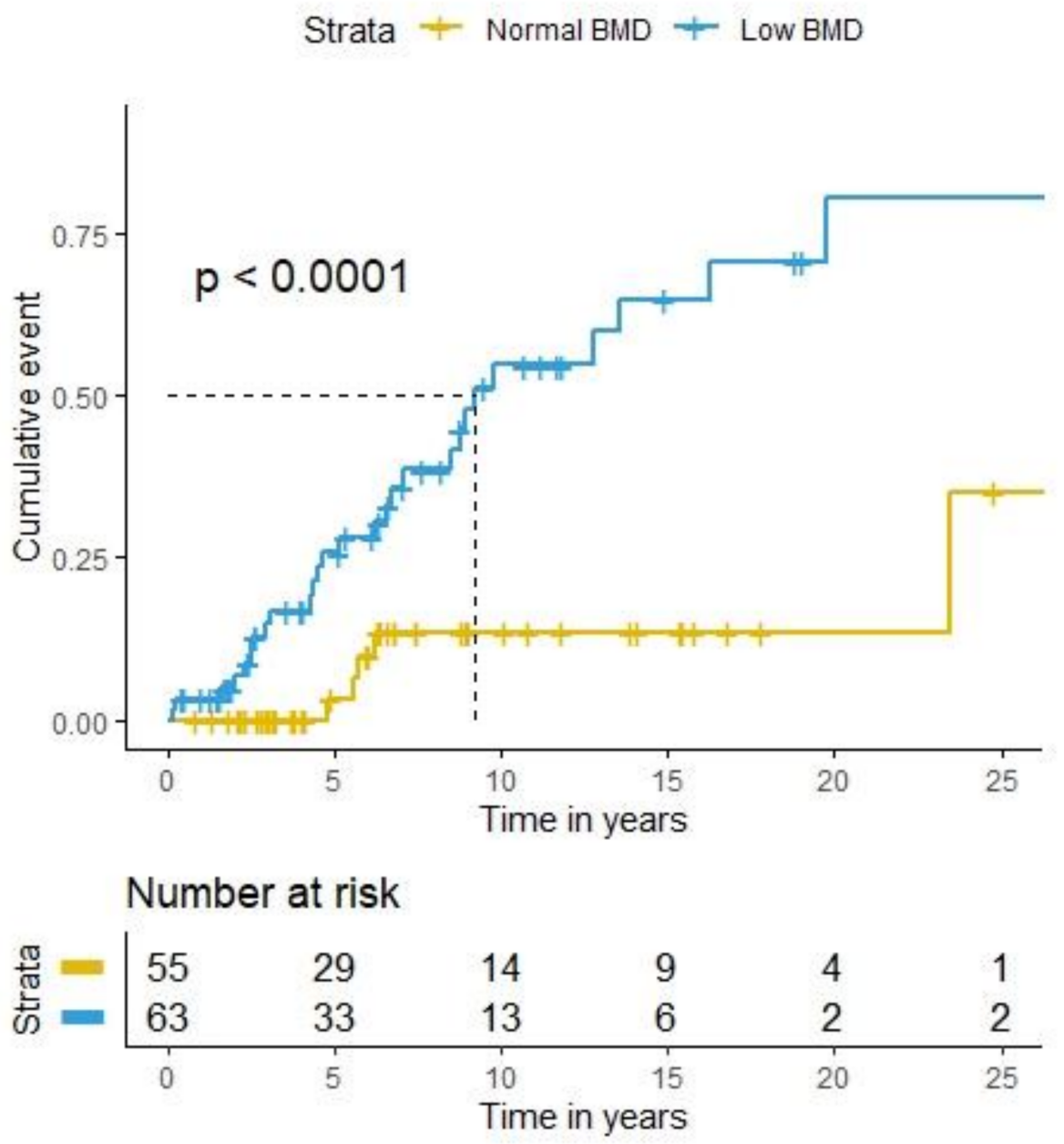

Figure 3. Kaplan-Meier curve of estimated cumulative fracture events for patients stratified by bone mineral density (normal BMD vs. low BMD). BMD = bone mineral density.

\section{Discussion}

Patients with chronic pancreatitis are at risk of osteoporosis and fracture because of numerous factors such as deteriorating pancreatic exocrine function, maldigestion and malabsorption of nutrients (especially fat-soluble vitamins and micronutrients), chronic systemic inflammation, abnormal bone turnover and, for some patients, ongoing alcohol excess and smoking [8]. We found low BMD in $53.4 \%$ (osteopenia $28.0 \%$ and osteoporosis $25.4 \%$ ) of patients during a mean follow-up of 7.6 years after diagnosis of CP (897.6 personyears), which is lower compared to studies from Ireland [8,9], Germany [10], USA [11] and India [12], but higher than experiences from the Czech Republic [13] (Table 4). A systematic review and meta-analysis that included 10 studies and 513 patients with $\mathrm{CP}$ showed a pooled prevalence rate for osteoporosis or osteopenia of $65 \%$ ( $23.4 \%$ prevalence for osteoporosis and $39.8 \%$ for osteopenia) [3]. However, most of the studies were heterogeneous and not amenable to subgroup analysis, with bias due to small sample size and selection bias leading to wide confidence intervals and statistical uncertainty (using the data on DXA after the fracture is a major selection bias in these kinds of studies) [1,3]. Furthermore, systematic reviews have shown clinical and methodological diversity regarding patient 
type, disease severity and assessment methods. Hence, any conclusions must be treated with caution [3].

Our study found fracture incidence was $44.4 \%(n=28)$ in patients with $\mathrm{CP}$ and low BMD; the percent was only $16.7 \%(n=5)$ in CP patients with normal BMD. Osteoporosis is a strong risk factor for fractures and there exists a knowledge gap on this topic in patients with CP [3]. In one noteworthy clinical study, Tignor et al. estimated the prevalence of fractures in $\mathrm{CP}$ compared to several gastrointestinal diseases. The authors reported a fracture rate of $4.8 \%$ in $\mathrm{CP}$, which can be compared to $1.1 \%$ in controls, $3.0 \%$ in Crohn's disease, $4.8 \%$ in liver cirrhosis and $5.0 \%$ in celiac disease [6]. A higher-than-average fracture rate was observed in $\mathrm{CP}$ patients compared to population-based controls in a study from Denmark [14]. In that study, the authors reported a higher relative risk of fractures in younger patients with liver cirrhosis and $\mathrm{CP}$, leading to the suggestion that bone loss can be an early component in the disease course. This finding would also corroborate Joshi et al. They demonstrated significantly lower BMD scores at the spine, hip and forearm in young patients with tropical pancreatitis (juvenile form of chronic calcific non-alcoholic pancreatitis, seen almost exclusively in the developing countries of the tropical world) [15]. The fracture rate in $\mathrm{CP}$ patients identified in our study was determined over a mean followup of 7.6 years and included all fracture incidences in the patient cohort. In contrast, Tignor et al. only included vertebral, hip or wrist fractures, and excluded patients with multiple gastrointestinal diagnoses. We included any first fracture in all patients being treated at our clinic. However, as DXA is a prerequisite for inclusion, this predisposes our cohort to another selection bias for patients with a higher risk of fractures. This concern was partly considered when patients with prior fractures were excluded from analysis. A large proportion of patients had suffered a fracture in the period between diagnosis of $\mathrm{CP}$ and DXA scan (16/33), inclining them to receive full osteoporotic work, which will have skewed our final cohort. Median time from CP diagnosis to DXA was similar between patients with low BMD and patients with normal BMD. Regardless, our data on the prevalence of fractures are higher and should be evaluated in other large cohorts of patients with $\mathrm{CP}$, given that it is an ultimate clinical outcome in low BMD.

For patients suffering fractures, treatment with three or more consecutive months with either vitamin D or PERT at any time point before fracture incidence suggested a significantly longer median time to first fracture for all patients. This finding is a new and exciting outcome of our study. Neither previous meta-analyses nor the HaPanEU European guidelines on CP have reviewed any published data on the effect of PERT on fracture risk. Given the dysregulated bone mineral metabolism that follows from severe malnutrition and trace mineral deficiencies, it seems reasonable that ameliorating poor uptake in vitamin and trace minerals could potentially improve BMD. However, until this can be studied in a prospective cohort or register-based cohort, it will remain a significant clinical knowledge gap [1,3].

The mean age in our cohort was 53 years and was significantly lower in patients with normal DXA compared to the low BMD group. Patients in most of the previous studies were younger (Table 4). Due to normal age-related bone loss, it would be expected that older patients (especially females) would have lower BMD. Previous meta-analyses have shown that osteoporosis is prevalent in relatively young patients with $\mathrm{CP}$ and no apparent association between age and BMD has been observed [3]. The young age of patients in studies from India can be partially explained by tropical CP, a condition associated with early clinical onset and malnutrition [15].

Females in our study were more prevalent in the low BMD group than in those with normal DXA results, which is another difference from other studies. Surprisingly, no meta-analysis has identified a relationship between sex and low BMD in patients with $\mathrm{CP}$, despite the fact that female sex (especially postmenopausal) is a known risk factor for low BMD [15]. 
DXA was performed in only $23 \%$ of our patients with definite $\mathrm{CP}$, showing low adherence to HaPanEU European CP guidelines. The guidelines recommend DXA every 2 years in patients with $\mathrm{CP}$ and low BMD [1].

To our knowledge, this is so far the largest single-centre study on a well-defined cohort of patients with clear differentiation between definite and probable $\mathrm{CP}$ and inclusion of patients with various aetiologies of $\mathrm{CP}$, thus representing the treatment reality of $\mathrm{CP}$ patients in a high-volume tertiary care centre. The long follow-up is an added strength of the study, as information on treatment and fractures fills the knowledge gaps on this important clinical entity. The major limitation of the study is its retrospective nature. Another important limitation is the lack of data on dietary intake and biomarkers of systemic inflammation. Due to the retrospective analysis, it was not possible to obtain data on DXA on the same date as CP diagnosis. This analysis is another limitation of our study, as well as possible selection bias due to the risk of confounding with patients with comorbidities. Finally, because of the low number of events (only five fractures in the normal BMD group and fourteen patients given PERT), the clinical significance of the influence of these drugs on reducing fracture risk is only suggestive. Our results can be used to inform power calculations for future studies on this topic, which could also include serial DXA with the whole-body composition and information on sarcopenia to evaluate the recently proposed "osteosarcopenia concept" [16], detailed dietary intake and follow-up of all anthropometric parameters, as well as bone resorption and bone modelling factors (biomarkers).

Table 4. Studies published on osteopathy in chronic pancreatitis.

\begin{tabular}{|c|c|c|c|c|c|c|c|}
\hline Author & Year & Country & $\mathbf{N}$ & Age & Sex & Aetiology/Results & Comments \\
\hline Moran [17] & 1997 & Argentina & 14 & 56 & $\begin{array}{l}\text { Not } \\
\text { mentioned }\end{array}$ & $\begin{array}{c}\text { Alcohol: } 71.4 \% \\
\text { Idiopathic } 28.6 \% \\
\text { Osteopathy: } 92.8 \% \\
\text { Osteopenia: } 71.4 \% \\
\text { Osteoporosis: } 21.4 \%\end{array}$ & $\begin{array}{l}\text { All included patients } \\
\text { with severe PEI. }\end{array}$ \\
\hline Haaber [18] & 2000 & Denmark & 58 & 54 & $55.2 \%$ male & $\begin{array}{c}\text { Alcohol: } 79 \% \\
56 \% \text { of patients in the } \\
\text { group without PEI and } \\
69 \% \text { in the group with PEI } \\
\text { had Z-scores of the } \\
\text { BMD }<-1\end{array}$ & $\begin{array}{l}\text { Conclusions: patients } \\
\text { with CP, particularly } \\
\text { patients with advanced } \\
\text { disease and steatorrhea, } \\
\text { are at risk of developing } \\
\text { significant bone loss }\end{array}$ \\
\hline Mann [19] & 2003 & Germany & 42 & 51.1 & All males & Not described & $\begin{array}{c}\text { Conclusion: } \\
\text { connection between the } \\
\text { inflammatory } \\
\text { destruction of the } \\
\text { pancreas (Cambridge } \\
\text { classification), exocrine } \\
\text { pancreatic insufficiency } \\
\text { (faecal } \\
\text { elastase 1), altered levels } \\
\text { of vitamin D metabolites } \\
\text { and loss of skeletal mass }\end{array}$ \\
\hline $\begin{array}{l}\text { Dujsikova } \\
\text { [13] }\end{array}$ & 2008 & $\begin{array}{l}\text { Czech } \\
\text { Republic }\end{array}$ & 73 & 46.6 & $76.7 \%$ males & $\begin{array}{l}\text { Osteopathy: } 39 \% \text {. } \\
\text { Osteopenia: } 26 \% \text {, } \\
\text { Osteoporosis: } 5 \% \text {, } \\
\text { Osteomalacia: } 8 \%\end{array}$ & $\begin{array}{l}\text { CP diagnosed with EUS } \\
\text { and defined as mild, } \\
\text { moderate and severe } \\
\text { (more than half of the } \\
\text { patients had mild CP) }\end{array}$ \\
\hline
\end{tabular}


Table 4. Cont.

\begin{tabular}{|c|c|c|c|c|c|c|c|}
\hline Author & Year & Country & $\mathbf{N}$ & Age & Sex & Aetiology/Results & Comments \\
\hline Sudeep [20] & 2011 & India & 31 & 35.8 & All males & $\begin{array}{l}\text { Tropical pancreatitis: } 65 \% \\
\text { Idiopathic: } 35 \% \\
29 \% \text { had a T-score of less } \\
\text { than }-2.5\end{array}$ & $\begin{array}{c}\text { Conclusion: Patients } \\
\text { with chronic pancreatitis } \\
\text { and a T-score of }<-2.5 \\
\text { had a significantly lower } \\
\text { BMI. } \\
\text { No correlation was } \\
\text { found between } 25(\mathrm{OH}) \mathrm{D} \\
\text { levels and BMD }\end{array}$ \\
\hline Joshi [15] & 2011 & India & $\begin{array}{l}72 \\
\text { (DXA } \\
\text { in 60) }\end{array}$ & 31 & $53 \%$ males & $\begin{array}{l}\text { All patients with tropical } \\
\text { calcific pancreatitis }\end{array}$ & $\begin{array}{l}\text { Conclusion: despite } \\
\text { their young age, patients } \\
\text { with tropical calcific } \\
\text { pancreatitis have } \\
\text { significantly } \\
\text { low BMD }\end{array}$ \\
\hline Duggan [9] & 2012 & Ireland & 53 & 48.7 & $75.5 \%$ males & $\begin{array}{c}\text { Alcohol was the cause of } \\
\text { disease in } 38.7 \% \text { of } \\
\text { patients. } \\
\text { (just over } 6 \% \text { of both } \\
\text { patients and controls } \\
\text { were never drinkers). } \\
\text { Osteopathy: } 73.6 \% \\
\text { Osteoporosis: } 34 \% \\
\text { Osteopenia: } 39.6 \%\end{array}$ & $\begin{array}{l}\text { Conclusion: a third of } \\
\text { the patients with CP had } \\
\text { osteoporosis, which was } \\
\text { more than triple the rate } \\
\text { in the matched control } \\
\text { group }\end{array}$ \\
\hline
\end{tabular}

Deficiencies of fat-soluble vitamins and a decreased BMD are

Alcohol: 50\% Idiopathic: $43 \%$

Other: $7 \%$

Osteoporosis: 10\% Osteopenia: $45 \%$ frequently present in $\mathrm{CP}$ even in

exocrine-sufficient patients. Consequently, all patients with $\mathrm{CP}$ should be routinely screened for fat-soluble vitamin deficiencies and a decreased BMD

Conclusion: both bone formation and bone resorption were raised in patients with $\mathrm{CP}$
Alcohol: $62.1 \%$ Idiopathic: $27.6 \%$ Other: $10.3 \%$

Osteoporosis: $31 \%$ Osteopenia: $44.8 \%$ compared to controls. This finding indicates that bone turnover was elevated in CP.

Those with alcohol-induced disease did not have lower BMD than those with CP of other aetiologies 
Table 4. Cont.

\begin{tabular}{|c|c|c|c|c|c|c|c|}
\hline Author & Year & Country & $\mathbf{N}$ & Age & Sex & Aetiology/Results & Comments \\
\hline $\begin{array}{c}\text { Prabhakaran } \\
\text { [12] }\end{array}$ & 2014 & India & 103 & 38.6 & All males & $\begin{array}{l}\text { Alcohol: } 70 \% \text {, Idiopathic: } \\
\text { 29.1\%; (one patient had } \\
\text { post-traumatic chronic } \\
\text { Pancreatitis) } \\
\text { Osteoporosis: } 30.1 \% \text {, } \\
\text { Osteopenia: } 39.8 \%\end{array}$ & $\begin{array}{l}\text { Conclusion: most } \\
\text { patients with both } \\
\text { alcoholic and idiopathic } \\
\text { had low BMD and the } \\
\text { frequency of bone } \\
\text { changes was similar } \\
\text { between calcific and } \\
\text { non-calcific groups, } \\
\text { diabetics and } \\
\text { nondiabetics, patients } \\
\text { with and without a } \\
\text { history of steatorrhea, } \\
\text { patients with and } \\
\text { without vitamin D } \\
\text { deficiency and across } \\
\text { different pancreatitis } \\
\text { severity groups }\end{array}$ \\
\hline Min [11] & 2014 & USA & 91 & 48.6 & $\begin{array}{c}62.6 \% \\
\text { females }\end{array}$ & $\begin{array}{c}\text { Toxic/metabolic: } 59.3 \% \\
\text { Idiopathic: } 18.6 \% \\
\text { Hereditary: } 14.3 \% \\
\text { Autoimmune: } 5.5 \% \\
\text { Osteopenia: } 46.7 \% \\
\text { Osteoporosis: } 22.2 \%\end{array}$ & $\begin{array}{l}\text { Conclusion: There is a } \\
\text { high prevalence of } \\
\text { fat-soluble vitamin } \\
\text { deficiencies, osteopathy } \\
\text { and malnutrition in CP } \\
\text { patients, which is } \\
\text { underestimated due to } \\
\text { the lack of effective } \\
\text { diagnosis and } \\
\text { suboptimal therapies for } \\
\text { EPI }\end{array}$ \\
\hline Haas [10] & 2015 & Germany & 15 & 45.2 & all males & $\begin{array}{c}\text { Alcohol: } 72 \% \\
\text { Osteoporosis: } 16 \% \\
\text { Osteopenia: } 76 \%\end{array}$ & $\begin{array}{c}\text { Conclusion: no } \\
\text { correlation between } \\
\text { bone metabolism and } \\
\text { elastase }\end{array}$ \\
\hline $\begin{array}{l}\text { Stigliano } \\
\text { [22] }\end{array}$ & 2018 & $\begin{array}{l}\text { European } \\
\text { multicen- } \\
\text { tric }\end{array}$ & 211 & 60 & $67 \%$ males & $\begin{array}{c}\text { Alcoholic: } 43 \% \\
\text { Idiopathic: } 19 \% \\
\text { Hereditary: } 4 \% \\
\text { Obstructive: } 5.7 \% \\
\text { Osteopenia: } 42 \% \\
\text { Osteoporosis: } 22 \%\end{array}$ & $\begin{array}{l}\text { Conclusion: vitamin } \\
\text { K deficiency is the only } \\
\text { factor associated with } \\
\text { osteoporosis in male } \\
\text { patients }\end{array}$ \\
\hline $\begin{array}{l}\text { Present } \\
\text { study }\end{array}$ & 2021 & Sweden & 118 & 53.1 & $\begin{array}{l}58.5 \% \\
\text { males }\end{array}$ & $\begin{array}{c}\text { Alcohol and smoking: } \\
\text { 33.9\% } \\
\text { Smoking only: } 11 \% \\
\text { Alcohol only: } 5.9 \% \\
\text { Hereditary: } 11.8 \% \\
\text { Immunological: } 14.4 \% \\
\text { Efferent duct factors: } 9.3 \% \\
\text { Low BMD: } 53.4 \%\end{array}$ & $\begin{array}{l}\text { Conclusion: } \\
\text { Low BMD was found in } \\
53.4 \% \text { of patients with } \\
\text { CP with a high } \\
\text { prevalence of fractures } \\
(44.4 \%) .\end{array}$ \\
\hline
\end{tabular}

$\mathrm{N}=$ number of patients included in the study; $\mathrm{CP}=$ chronic pancreatitis; $\mathrm{PEI}=$ pancreatic exocrine insufficiency; $\mathrm{BMD}=$ bone mineral density; DXA = dual-energy X-ray absorptiometry; PERT = pancreatic enzyme replacement therapy.

\section{Conclusions}

In this study, DXA was performed in only $23 \%$ of patients with definite $\mathrm{CP}$, showing a low adherence to HaPanEU European guidelines on CP. A low BMD was seen in $53.4 \%$ of patients with $\mathrm{CP}$, and $44 \%$ of the patients with a low BMD experienced a fracture during follow-up. Moreover, the fracture rate in patients with low BMD was increased compared to patients with normal BMD. Considering the frequency and clinical importance of fractures 
in $\mathrm{CP}$ and the potentially positive effect of lifestyle modification, environmental factors and secondary prevention, it is worthwhile to create patient and physician awareness of this clinical entity. As PEI has been associated with a lower BMD, it remains imperative to conduct prospective studies on the role of PERT as a cornerstone in the treatment of PEI.

Supplementary Materials: The following are available online at https:/ /www.mdpi.com/article/10 $.3390 /$ nu13072386/s1, Figure S1: Kaplan-Maier curves of cumulative fracture events for all patients, Table S1: Cox regression analysis adjusted hazard ratio (aHR) of fracture events in patients treated with PERT, PPI, Vitamin D, Metformin, Opioids or Steroids during 90 or more consecutive daily regular treatments at any time before the fracture event.

Author Contributions: Study conception and design, M.V., J.-M.L.; acquisition of data, L.N.D., E.A., W.R., M.K., A.D., M.V., I.D., M.S.; statistical analysis, E.A., W.R., H.H.; drafting and writing of the manuscript, all authors; guarantor of the article, M.V. and J.-M.L. All authors approved the final version of the article, including the authorship list. All authors have read and agreed to the published version of the manuscript.

Funding: This study received no external funding.

Institutional Review Board Statement: The study was approved by the Regional Ethics Committee (Swedish: Regional Etikprövningsnämnden) in Stockholm, Dnr: 2020-02209. The requirement for individual informed patient consent was waived by the committee owing to the nature of a retrospective study and that patients were not directly involved.

Informed Consent Statement: Not applicable.

Data Availability Statement: Our dataset contains sensible data which may contain private information about the patients treated at out clinic. The dataset can therefore not be made available to the public. However, the data used in our study can be provided upon request.

Acknowledgments: This study was supported by the Swedish Association for the Advancement of Pancreatology (SweSup).

Conflicts of Interest: M.K.,E.A., L.N.D., A.D., W.R., H.H., M.S., I.D.: none. M.V.: lecture fees Mylan, Abbott. J.-M.L.: lecture fees Mylan, Abbott. The authors declare no conflict of interest regarding the present study.

\footnotetext{
Abbreviations

$\mathrm{BMD}=$ bone mineral density; $\mathrm{BMI}=$ body mass index; $\mathrm{CI}=$ confident interval; $\mathrm{CP}=$ chronic pancreatitis; $\mathrm{DM}=$ diabetes mellitus; DXA = dual-energy X-ray absorptiometry; ICD = international classification of diseases; $\mathrm{HR}$ = hazard ratio; $\mathrm{aHR}=$ adjusted $\mathrm{HR}$; $\mathrm{PEI}=$ pancreatic exocrine insufficiency; PERT = pancreatic enzyme replacement therapy; $\mathrm{PPI}=$ proton-pump inhibitor; $\mathrm{SD}=$ standard deviation .
}

\section{References}

1. Löhr, J.M.; Dominguez-Munoz, E.; Rosendahl, J.; Besselink, M.; Mayerle, J.; Lerch, M.M.; Haas, S.; Akisik, F.; Kartalis, N.; Iglesias-Garcia, J.; et al. United european gastroenterology evidence-based guidelines for the diagnosis and therapy of chronic pancreatitis (hapaneu). United Eur. Gastroenterol. J. 2017, 5, 153-199. [CrossRef]

2. Peck, W.A. Consensus development conference: Diagnosis, prophylaxis, and treatment of osteoporosis. Am. J. Med. 1993, 94, 646-650. [CrossRef]

3. Duggan, S.N.; Smyth, N.D.; Murphy, A.; Macnaughton, D.; O'Keefe, S.J.; Conlon, K.C. High prevalence of osteoporosis in patients with chronic pancreatitis: A systematic review and meta-analysis. Clin. Gastroenterol. Hepatol. 2014, 12, 219-228. [CrossRef] [PubMed]

4. Kanakis, A.; Vipperla, K.; Papachristou, G.I.; Brand, R.E.; Slivka, A.; Whitcomb, D.C.; Yadav, D. Bone health assessment in clinical practice is infrequenty performed in patients with chronic pancreatitis. Pancreatology 2020, 20, 1109-1114. [CrossRef] [PubMed]

5. Kanis, J.A.; Cooper, C.; Rizzoli, R.; Reginster, J.Y. European guidance for the diagnosis and management of osteoporosis in postmenopausal women. Osteoporos. Int. 2019, 30, 3-44. [CrossRef] [PubMed]

6. Tignor, A.S.; Wu, B.U.; Whitlock, T.L.; Lopez, R.; Repas, K.; Banks, P.A.; Conwell, D. High prevalence of low-trauma fracture in chronic pancreatitis. Am. J. Gastroenterol. 2010, 105, 2680-2686. [CrossRef] 
7. Schneider, A.; Löhr, J.M.; Singer, M.V. The m-annheim classification of chronic pancreatitis: Introduction of a unifying classification system based on a review of previous classifications of the disease. J. Gastroenterol. 2007, 42, 101-119. [CrossRef]

8. Duggan, S.N.; Purcell, C.; Kilbane, M.; O’Keane, M.; McKenna, M.; Gaffney, P.; Ridgway, P.F.; Boran, G.; Conlon, K.C. An association between abnormal bone turnover, systemic inflammation, and osteoporosis in patients with chronic pancreatitis: $\mathrm{A}$ case-matched study. Am. J. Gastroenterol. 2015, 110, 336-345. [CrossRef] [PubMed]

9. Duggan, S.N.; O'Sullivan, M.; Hamilton, S.; Feehan, S.M.; Ridgway, P.F.; Conlon, K.C. Patients with chronic pancreatitis are at increased risk for osteoporosis. Pancreas 2012, 41, 1119-1124. [CrossRef] [PubMed]

10. Haas, S.; Krins, S.; Knauerhase, A.; Löhr, M. Altered bone metabolism and bone density in patients with chronic pancreatitis and pancreatic exocrine insufficiency. Jop 2015, 16, 58-62.

11. Min, M.; Patel, B.; Han, S.; Bocelli, L.; Kheder, J.; Vaze, A.; Wassef, W. Exocrine pancreatic insufficiency and malnutrition in chronic pancreatitis: Identification, treatment, and consequences. Pancreas 2018, 47, 1015-1018. [CrossRef]

12. Prabhakaran, A.; Bhasin, D.K.; Rana, S.S.; Bhadada, S.K.; Bhansali, A.; Rao, C.; Gupta, R.; Khandelwal, N. Bone mineral metabolism and bone mineral density in alcohol related and idiopathic chronic pancreatitis. Trop. Gastroenterol. 2014, 35, 107-112. [CrossRef]

13. Dujsikova, H.; Dite, P.; Tomandl, J.; Sevcikova, A.; Precechtelova, M. Occurrence of metabolic osteopathy in patients with chronic pancreatitis. Pancreatology 2008, 8, 583-586. [CrossRef]

14. Bang, U.C.; Benfield, T.; Bendtsen, F.; Hyldstrup, L.; Beck Jensen, J.E. The risk of fractures among patients with cirrhosis or chronic pancreatitis. Clin. Gastroenterol. Hepatol. 2014, 12, 320-326. [CrossRef]

15. Joshi, A.; Reddy, S.V.; Bhatia, V.; Choudhuri, G.; Singh, R.K.; Singh, N.; Bhatia, E. High prevalence of low bone mineral density in patients with tropical calcific pancreatitis. Pancreas 2011, 40, 762-767. [CrossRef]

16. Hirschfeld, H.P.; Kinsella, R.; Duque, G. Osteosarcopenia: Where bone, muscle, and fat collide. Osteoporos. Int. 2017, 28, 2781-2790. [CrossRef]

17. Morán, C.E.; Sosa, E.G.; Martinez, S.M.; Geldern, P.; Messina, D.; Russo, A.; Boerr, L.; Bai, J.C. Bone mineral density in patients with pancreatic insufficiency and steatorrhea. Am. J. Gastroenterol. 1997, 92, 867-871. [PubMed]

18. Haaber, A.B.; Rosenfalck, A.M.; Hansen, B.; Hilsted, J.; Larsen, S. Bone mineral metabolism, bone mineral density, and body composition in patients with chronic pancreatitis and pancreatic exocrine insufficiency. Int. J. Pancreatol. 2000, $27,21-27$. [CrossRef]

19. Mann, S.T.; Stracke, H.; Lange, U.; Klör, H.U.; Teichmann, J. Alterations of bone mineral density and bone metabolism in patients with various grades of chronic pancreatitis. Metabolism 2003, 52, 579-585. [CrossRef]

20. Sudeep, K.; Chacko, A.; Thomas, N.; Selvakumar, R.; George, B.; Paul, T.V.; Seshadri, M.S. Predictors of osteodystrophy in patients with chronic nonalcoholic pancreatitis with or without diabetes. Endocr. Pract. 2011, 17, 897-905. [CrossRef] [PubMed]

21. Sikkens, E.C.; Cahen, D.L.; Koch, A.D.; Braat, H.; Poley, J.W.; Kuipers, E.J.; Bruno, M.J. The prevalence of fat-soluble vitamin deficiencies and a decreased bone mass in patients with chronic pancreatitis. Pancreatology 2013, 13, 238-242. [CrossRef] [PubMed]

22. Stigliano, S.; Waldthaler, A.; Martinez-Moneo, E.; Lionetto, L.; Robinson, S.; Malvik, M.; Hedstrom, A.; Kaczka, A.; Scholdei, M.; Haas, S.; et al. Vitamins $\mathrm{d}$ and $\mathrm{k}$ as factors associated with osteopathy in chronic pancreatitis: A prospective multicentre study (p-bone study). Clin. Transl. Gastroenterol. 2018, 9, 197. [CrossRef] [PubMed] 